Published in final edited form as:

J Am Chem Soc. 2016 February 3; 138(4): 1265-1272. doi:10.1021/jacs.5b11294.

\title{
Aerobic Linear Allylic C-H Amination: Overcoming Benzoquinone Inhibition
}

\author{
Christopher C. Pattillo $\ddagger$, Iulia I. Strambeanu ${ }^{\ddagger}$, Pilar Calleja $^{\nabla}$, Nicolaas A. Vermeulen $^{\perp}$, \\ Tomokazu Mizuno ${ }^{\S}$, and M. Christina White ${ }^{\ddagger},{ }^{*}$ \\ ‡Roger Adams Laboratory, Department of Chemistry, University of Illinois, Urbana, Illinois, 61801, \\ United States
}

\begin{abstract}
An efficient aerobic linear allylic $\mathrm{C}-\mathrm{H}$ amination reaction (LAA) is reported under $\mathrm{Pd}(\mathrm{II}) / \mathrm{bis}-$ sulfoxide/Brønsted base catalysis. The reaction operates under preparative, operationally simple conditions ( 1 equiv. olefin, 1 atm. $\mathrm{O}_{2}$ or air), with reduced $\mathrm{Pd}(\mathrm{II}) / \mathrm{bis}$-sulfoxide catalyst loadings while providing higher turnovers and product yields than systems employing stoichiometric benzoquinone (BQ) as the terminal oxidant. Palladium(II)/benzoquinone $\pi$-acidic interactions have been invoked in various catalytic processes and are often considered beneficial in promoting reductive functionalizations. When such electrophilic activation for functionalization is not needed, however, benzoquinone at high concentrations may compete with crucial ligand (bissulfoxide) binding and inhibit catalysis. Kinetic studies reveal an inverse relationship between the reaction rate and the concentration of $\mathrm{BQ}$, suggesting that benzoquinone is acting as a ligand for $\mathrm{Pd}(\mathrm{II})$ which results in an inhibitory effect on catalysis.
\end{abstract}

\section{Graphical Abstract}

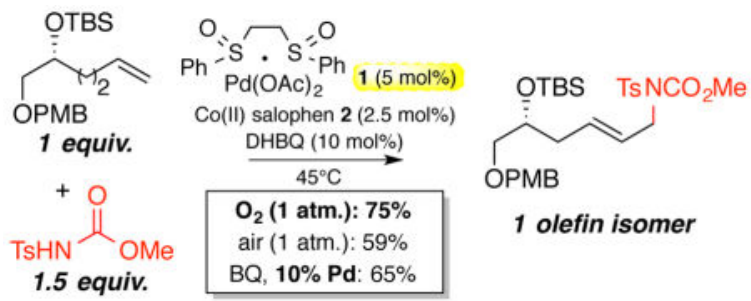

\section{Keywords}

Amination; C-H oxidation; Palladium; Sulfoxide; Oxygen; Benzoquinone; Air; Cobalt; Vanadium

\footnotetext{
"Corresponding Author: mcwhite7@illinois.edu.

Institute of Chemical Research of Catalonia (ICIQ), Av. Països Catalans 16, 43007 Tarragona, Spain.

${ }^{\perp}$ Department of Chemistry, Northwestern University, 2145 Sheridan Road, Evanston IL, USA.

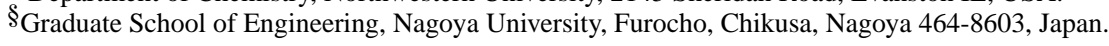

Author Contributions

All authors have given approval to the final version of the manuscript.

Supporting Information. Experimental procedures, characterization data, and copies of ${ }^{1} \mathrm{H}$ and ${ }^{13} \mathrm{C}$ NMR spectra for all new compounds. This material is available free of charge via the Internet at http://pubs.acs.org.
} 


\section{INTRODUCTION}

Nature routinely uses molecular oxygen $\left(\mathrm{O}_{2}\right)$ as a stoichiometric oxidant for metalloenzyme catalyzed $\mathrm{C}-\mathrm{H}$ bond oxidations. ${ }^{1}$ In the context of chemical synthesis, the economic and environmental advantages of using $\mathrm{O}_{2}$ for these purposes are clear: $\mathrm{O}_{2}$ is an abundant, highly atom-efficient oxidant per weight that generates no toxic byproducts. ${ }^{2}$ Less evident, however, is the potential for employing this oxidant in a manner that would increase the catalytic efficiency of oxidation reactions.

Since an early report that benzoquinone (BQ) is capable of acting as an effective stoichiometric oxidant for Pd-catalyzed olefin oxidations, BQ has become the most common terminal oxidant for palladium-catalyzed oxidations proceeding via $\mathrm{Pd}(\mathrm{II}) / \mathrm{Pd}(0)$ redox cycles. ${ }^{3,4} \mathrm{We}$ and others have demonstrated that at BQ may fill a dual role in palladiumcatalyzed $\mathrm{C}-\mathrm{H}$ oxidation reactions by acting as both an oxidant and a $\pi$-acidic ligand to promote reductive eliminations at the metal. ${ }^{5}$ Allylic $\mathrm{C}-\mathrm{H}$ oxidations that benefit from this effect operate under the principle of serial ligand catalysis, wherein distinct ligands promote specific steps along a catalytic cycle (Scheme 1A). ${ }^{5 \mathrm{c}}$ Under these conditions, the reversibly coordinating bis-sulfoxide ligand coordinates to $\mathrm{Pd}(\mathrm{II})$ to promote a $\mathrm{C}-\mathrm{H}$ cleavage step and generate a reactive $\pi$-allylPd(II) intermediate. Benzoquinone may then coordinate to this electrophilic intermediate via an $\eta^{2}-\pi$ complex and act as a $\pi$-acidic ligand to promote reductive eliminations at the metal center. ${ }^{5}$ We hypothesized that when activation of the electrophilic metal center is not required for functionalization, these BQ-Pd(II) $\mathrm{L}_{n}$ interactions may prove detrimental in systems using weakly coordinating ligands. By competing with the essential bis-sulfoxide binding event at the metal, BQ binding at high concentrations may lead to an inhibitory effect on catalysis.

Herein, we describe the development of an efficient intermolecular linear allylic $\mathrm{C}-\mathrm{H}$ amination reaction employing a cobalt-mediated redox-relay catalytic cycle that uses molecular oxygen as the terminal oxidant under mild $\left(1 \mathrm{~atm} ., 45^{\circ} \mathrm{C}\right)$ and preparatively useful conditions ( 1 equiv. olefin, 1.5 equiv. nitrogen nucleophile). This improved system enables the reaction to proceed with catalytic quantities of benzoquinone, thus reducing the potential for inhibitory binding of $\mathrm{BQ}$ to the Pd(II)-catalyst. As a result, this system affords higher or comparable yields while operating at lower catalyst loadings than those previously developed using super-stoichiometric BQ as the terminal oxidant. The aerobic linear allylic amination reaction even remains operational at reduced oxygen concentrations found in air. Kinetic experiments substantiate the hypothesis of an inhibitory BQ effect at high concentrations and indicate that the improved efficiency of the aerobic system results from the low concentration of benzoquinone present in the reaction mixture.

\section{DESIGN PRINCIPLES}

Palladium(II)/bis-sulfoxide catalysis has emerged as a general platform for allylic $\mathrm{C}-\mathrm{H}$ oxidations, aminations, dehydrogenations, halogenations, and alkylations of a-olefins. ${ }^{6,7}$ Common to all of these $\mathrm{C}-\mathrm{H}$ functionalization reactions is the use of $10 \mathrm{~mol} \% \mathrm{Pd}$ bissulfoxide catalyst and stoichiometric quinone oxidants such as BQ. Additionally, the majority of these reactions exploit benzoquinone as a $\pi$-acidic ligand, often in combination 
with Lewis or Brønsted acid co-catalysts, to activate the electrophilic $\pi$-allylPd intermediate towards functionalization. $5,6 \mathrm{~h}, 7 \mathrm{a}$

Given the ubiquity of nitrogen functionality in bioactive compounds, its selective and general introduction represents a particularly powerful synthetic strategy. ${ }^{8}$ We disclosed a catalytic Brønsted base activation mode for the intermolecular linear allylic $\mathrm{C}-\mathrm{H}$ amination (LAA) reaction that proceeds via activation of the nitrogen nucleophile. ${ }^{7 \mathrm{~b}}$ Importantly, this reaction is no longer dependent on the $\pi$-acidic effect of benzoquinone for functionalization. Under these conditions, we noted a slight increase in reaction yield when a bulky quinonehaving diminished ability to coordinate to Pd- was employed as a terminal oxidant. ${ }^{7 \mathrm{~b}}$ With these considerations in mind, we chose the LAA reaction as a platform to evaluate the hypothesis that replacing benzoquinone with $\mathrm{O}_{2}$ as a stoichiometric oxidant can improve the catalytic efficiency of $\mathrm{Pd}(\mathrm{II})$-catalyzed oxidations with catalysts employing weakly coordinating ligands.

While a variety of important palladium-catalyzed oxidations of alcohols and olefins have been developed using $\mathrm{O}_{2}$ as a stoichiometric oxidant, analogous $\mathrm{C}-\mathrm{H}$ oxidation processes are scarce. ${ }^{4,9-14}$ Palladium (II)-catalyzed $\mathrm{C}-\mathrm{H}$ oxidation reactions often proceed with no formal ligands [e.g. $\mathrm{Pd}(\mathrm{OAc})_{2}$ ] or weakly coordinating, oxidatively stable ligands such as bis-sulfoxide. ${ }^{10}$ For allylic $\mathrm{C}-\mathrm{H}$ acetoxylations and aminations under such conditions, the slow electron transfer directly between $\mathrm{Pd}(0)$ and $\mathrm{O}_{2}$ relative to the rapid formation of palladium black via precipitation of palladium metal is thought to result in deleterious olefin isomerization processes and contribute to the requirement for high catalyst loadings. ${ }^{11-14}$ While aerobic $\mathrm{Pd}(\mathrm{II})$-catalyzed linear allylic $\mathrm{C}-\mathrm{H}$ aminations have been reported, their utility is limited by requirements such as excess alkene (e.g. 3-7 equiv. relative to nucleophile), high Pd catalyst loadings (e.g. 10-20 mol\%), and elevated pressures (e.g. 6-10 atm. $\mathrm{O}_{2}$ or air). ${ }^{12,13}$ Significant amounts of double bond isomerization in both the starting materials and products (up to 50\%) necessitate the use of large excesses of olefin and limit applications in fine chemical synthesis. ${ }^{12-14}$

We considered two possible strategies for engaging molecular oxygen as the terminal oxidant for the linear allylic amination reaction (LAA) under preparatively useful conditions. While oxidatively stable ligands which promote direct oxidation of $\operatorname{Pd}(0)$ with molecular oxygen have been developed, these ligands have not yet demonstrated the same generality in $\mathrm{C}-\mathrm{H}$ oxidation processes as compared to the bis-sulfoxide ligand class. ${ }^{2 \mathrm{a}, 4,15}$ A more general approach, compatible with the continued use of bis-sulfoxides, would be through the use of redox-active co-catalysts that act as electron transfer reagents to relay electrons from $\mathrm{Pd}(0)$ to $\mathrm{O}_{2}$ at rates that compete with $\mathrm{Pd}(0)$ precipitation (Scheme 2). An early example of this is seen in the Pd(II)-catalyzed Wacker oxidation of ethylene to acetaldehyde that uses catalytic $\mathrm{Cu}(\mathrm{II}) \mathrm{Cl}_{2}$ to shuttle electrons from $\mathrm{Pd}(0)$ to $\mathrm{O}_{2} \cdot{ }^{16}$ Unfortunately, unligated metal salts generally have a deleterious effect on $\mathrm{Pd}(\mathrm{II}) / \mathrm{bis}$ sulfoxide catalysis, possibly by sequestering the bis-sulfoxide ligand that binds weakly and reversibly to Pd(II). Alternatively, a variety of base metal complexes with covalent, nonexchangeable ligands are known to catalyze the oxidation of dihydroquinones to the corresponding quinones with $\mathrm{O}_{2} \cdot{ }^{17,18} \mathrm{In}$ a notable series of seminal publications, Bäckvall and co-workers demonstrated that this form of redox-relay catalysis enabled catalytic 
quantities of benzoquinone to be effective at regenerating $\mathrm{Pd}(\mathrm{II})(\mathrm{OAc})_{2}$ catalysts for the 1,4diacetoxylation of dienes, acetoxylation of cyclohexene, and oxidation of terminal olefins to methyl ketones. ${ }^{19}$ Mechanistic studies of processes proceeding via serial ligand catalysis have demonstrated that high concentrations of $B Q$ are required to effectively interact with the $\mathrm{Pd}(\mathrm{II})$ species to promote $\pi$-allyl Pd(II) functionalizations. ${ }^{5 \mathrm{c}, \mathrm{f}, \mathrm{g}}$ Collectively, this led us to hypothesize that in the context of an aerobic redox-relay catalytic cycle, the low concentration of BQ present would diminish its ability to effectively compete with the bissulfoxide ligand for $\mathrm{Pd}(\mathrm{II})$ but would remain an efficient electron carrier for $\mathrm{Pd}(0) / \mathrm{Pd}(\mathrm{II})$ reoxidation.

\section{REACTION DEVELOPMENT}

An efficient aerobic LAA process ( 1 equiv. olefin, reduced Pd catalyst loadings, $1 \mathrm{~atm} . \mathrm{O}_{2}$ ) was first evaluated with a series of established redox-active co-catalysts. At reduced catalyst loading ( $5 \mathrm{~mol} \%)$, a substantial diminishment in yield is observed under standard LAA conditions using stoichiometric BQ as the oxidant (Table 1, entries $\mathbf{1}$ versus 2). In contrast, the combination of $\mathrm{Co}$ (salophen) $(2.5 \mathrm{~mol} \%) /$ dihydroquinone (10 mol\%) under a balloon of $\mathrm{O}_{2}$ (1 atm.) allowed for the Pd/bis-sulfoxide 1 catalyst loading to be cut in half (10 mol\% to $5 \mathrm{~mol} \%$ ) and the nitrogen nucleophile loadings reduced ( 2 equiv. to 1.5 equiv.) with no diminishment in selectivity while maintaining a good yield (entries $\mathbf{3}$ and $\mathbf{4}$ versus $\mathbf{1}$ ). We were also encouraged by the observation that, under these optimized conditions, no significant decrease in yield was observed after reducing the reaction time to 24 hours (79\% versus $78 \%$ yield, entry 4). A series of other base metal co-catalysts were evaluated, however none were found to be more efficient than Co(salophen) 2 (entries 5-8). Interestingly, $\mathrm{VO}(\mathrm{acac})_{2} 3 / \mathrm{DHBQ}$ in THF solvent appeared to be equally effective as a redox co-catalyst system to $\mathrm{Co}$ (salophen) 2/DHBQ, albeit at higher loadings of nitrogen nucleophile (1.5 equiv. versus 2 equiv., entries 9 and 10). Although never explored in aerobic $\mathrm{Pd}$ (II)-catalyzed reactions, $\mathrm{VO}(\mathrm{acac})_{2} \mathbf{3}$ had been reported to catalyze the aerobic oxidation of hydroquinones to quinones at ambient temperatures and pressures of $\mathrm{O}_{2} \cdot{ }^{18}$ We were initially encouraged by the observation that the vanadium co-catalyst loading could be reduced to $1 \mathrm{~mol} \%$ with no diminishment in yield, suggesting it is an efficient electrontransfer agent (entry 10). Additional vanadium catalysts were also evaluated (entries 11-13), and under these conditions only $\mathrm{VOSO}_{4}$ was comparable to $\mathrm{VO}(\mathrm{acac})_{2} \mathbf{3}$, affording a $65 \%$ yield of the desired product (entry 13). Omission of the redox co-catalyst under these aerobic conditions resulted in significantly diminished yields, confirming its central role in $\mathrm{Pd}(\mathrm{II}) /$ bis-sulfoxide 1 catalyst regeneration (entry 14). The $\mathrm{Pd}(\mathrm{OAc})_{2} / 4,5$-diazafluorene-9one (DAF) system known to enable linear allylic acetoxylations using $\mathrm{O}_{2}$ as the terminal oxidant provided only trace quantities of aminated product under these conditions (entry 15). ${ }^{15}$ Notably, when using stoichiometric amounts of bulky 2,5-dimethyl benzoquinone (2,5-DMBQ) as a terminal oxidant, where methyl groups shield both olefin faces from binding to Pd, we observed comparable yields to the aerobic conditions (Table 1, entry 4 vs. entry 16). 


\section{REACTION SCOPE}

We began our investigations into the scope and reproducibility of the aerobic linear allylic $\mathrm{C}$ - H amination (LAA) with a variety of unactivated a-olefins, the most challenging substrates for amination (Table 2). Both the Co(salophen) 2 and $\mathrm{VO}(\mathrm{acac})_{2} 3$ redox cocatalyst systems were evaluated under fragment-coupling stoichiometries of olefin (1 equiv. terminal olefin and 1.5 or 2 equiv. nitrogen nucleophile). It is significant to note that these preparative conditions contrast those of previously reported aerobic allylic $\mathrm{C}-\mathrm{H}$ amination methods (vida supra). ${ }^{12,13}$

When comparing the $\mathrm{Co}$ (salophen) 2 and $\mathrm{VO}(\mathrm{acac})_{2} 3$ redox co-catalysts over a range of substrates at reduced Pd/bis-sulfoxide 1 catalyst loadings ( $5 \mathrm{~mol} \%$ ), we found both furnished products generally in excellent regio- and stereoselectivities (>20:1 linear:branched and $>20: 1 \mathrm{E:Z}$ ). The system employing cobalt uniformly furnished allylic amination products with higher turnover numbers (TON) and product yields comparable to or exceeding those using BQ. ${ }^{7}$ For example, substrates with branching oxygen, carbon, or nitrogen functionality in the homoallylic or bis-homoallylic positions (Table 2, entries 5-8) proceed on average with 17\% higher isolated yields and average TON of 14.6 versus average TON of 5.7 when compared to the $\mathrm{Pd} /$ bis-sulfoxide $1 / \mathrm{Cr}$ (salen) catalyzed system using BQ as a stoichiometric oxidant. ${ }^{7 \mathrm{a}}$ Additionally, for substrates where a direct comparison can be made with previously reported aerobic LAAs, the same trend in yields and turnover numbers is observed (entries 3 and 4). ${ }^{12}$ We also note that higher yielding substrates can be run for 24 hours without a significant decrease in yield (entries 3 and 7 ). The mass balance for these reactions is generally high, with unbranched substrates (e.g. entries 1-3) furnishing predominantly linear $E$-allylic amine ( $L: B=20: 1,11: 1$, and $15: 1$ respectively) and small quantities of isomerized recovered starting material (entries $\mathbf{1}$ and $\mathbf{3}, 11 \%$ and $4 \%$ respectively). Branched substrates (e.g. entry 7) give isomerically pure products and small amounts of recovered starting material as a mixture of isomerized (ca. 9\%) and isomerically pure terminal olefin (ca. 10\%) (see supporting information, Table 2, entry 7).

Unfortunately, the $\mathrm{VO}(\mathrm{acac})_{2} \mathbf{3}$ system proved to be less robust, generally providing linear allylic amine products in diminished yields and with significantly lower reproducibility between experiments than the cobalt system (see Table 2 entry 2 standard deviation and supporting information). Although in several cases yields for the vanadium system were comparable (entries 4, 7, and 8; Scheme 4) or even exceeded (entry 3 ) those of the cobalt system, no clear trend emerged for predicting these observed differences in reaction efficiency (see supporting information).

We next investigated the reactivity of the new aerobic LAA system for a variety of activated allylarene substrates (Table 3). Under these conditions, both electron poor and electron rich aromatic rings are well tolerated, furnishing products as one olefin isomer in good to excellent yields (entries 1-3). Additionally, efficient reactivity is observed for highly functionalized, electron rich aromatic systems (entries $\mathbf{4}$ and $\mathbf{5}$ ). Tolerance for medicinally relevant heterocyclic aromatic functionality is demonstrated in the aerobic LAA of an indole heterocycle (entry 6). In some cases, reactions may be run for 24 hours without a significant decrease in yield (entries $\mathbf{4}$ and $\mathbf{5}$ ). We were also pleased to find that often the Pd catalyst 
loading could be further reduced to $2.5 \mathrm{~mol} \%$ while still maintaining useful yields of aminated product (entries 1-5). In general, under these aerobic conditions, the yields and TONs are significantly higher than those of the benzoquinone system (entries $\mathbf{4}$ and $\mathbf{5}$ ). When comparing these results with a previous aerobic system, we again observe higher catalyst turnover numbers and product yields (entry $\mathbf{1}) .{ }^{12}$

It was previously demonstrated that substrates containing sensitive terminal epoxides and unprotected alcohols may be aminated with the base promoted LAA reaction in useful yields. ${ }^{7 \mathrm{~b}}$ A potential limitation of this aerobic linear allylic amination system, which employs a Lewis-acidic redox co-catalyst, is poor tolerance of highly Lewis basic functionality. Under our optimized aerobic LAA conditions employing the Co(salophen) 2 co-catalyst, we obtained a lower (ca. 30\%) yield for a terminal epoxide substrate (Table 3, entry 7). We attribute this diminished reactivity to deleterious side reactions of the terminal epoxide in the presence of the Lewis acidic cobalt co-catalyst. Analogous Co(salen) complexes are known to catalyze ring opening reactions of terminal epoxides with water. ${ }^{20}$ Additional attempts to use the $\mathrm{VO}(\mathrm{acac})_{2}$ system with a similar terminal epoxide substrate led to no significant improvement in yield. We next looked to conditions employing the sterically hindered quinone oxidant 2,5-DMBQ, which had shown equal efficiency to the aerobic conditions at reduced palladium loadings (Table 1, entry 16), and found that $\mathrm{C}-\mathrm{H}$ amination proceeded in $68 \%$ yield after 24 hours (entry 7 ). This constitutes a nearly $15 \%$ increase in yield relative to stoichiometric benzoquinone conditions run with twice the palladium loading and longer reaction times $(72 \mathrm{~h}){ }^{7 \mathrm{~b}}$ This result illustrates the complementarity of a bulky, readily available quinone to our aerobic conditions, allowing for efficient amination of substrates containing Lewis-acid sensitive functionality.

\section{Reactivity with Reduced $\mathrm{O}_{2}$ Concentrations}

We next sought to assess the efficiency of the aerobic LAA conditions under reduced concentrations of $\mathrm{O}_{2}$ considered beneficial for application of such aerobic chemistry in the synthesis of fine chemicals (Table 4). ${ }^{21}$ The aerobic LAA reaction was evaluated under identical conditions of temperature, pressure and catalyst loadings $\left(45^{\circ} \mathrm{C}, 1 \mathrm{~atm} ., 5-2.5 \mathrm{~mol}\right.$ $\%$ ), now at the significantly reduced $\mathrm{O}_{2}$ concentrations found in air.

The aerobic LAA run with air furnished aliphatic and aromatic aminated products with the same isomeric purities while maintaining synthetically useful yields at 1 equiv. of substrate and low catalyst loadings. Yields of aminated products were generally diminished relative to those of the analogous system using $\mathrm{O}_{2}$. Decreasing the catalyst loadings from $5 \mathrm{~mol} \%$ to $2.5 \mathrm{~mol} \%$ with aromatic substrates in some cases still allowed for a useful reaction to proceed (entries 5-7). These findings demonstrate that the $\mathrm{DHBQ} / \mathrm{Co}\left(\right.$ salophen) $/ \mathrm{O}_{2}$ redoxrelay is able to remain operative even under reduced concentrations of molecular oxygen. Whereas focused reaction optimization to develop an aerobic LAA using air is an important future goal, it is significant to note that for the majority of substrates run under air, aminated products were generated in comparable yields with higher TONs relative to the LAA using stoichiometric BQ oxidant. ${ }^{7}$ 


\section{Late Stage C-H Amination and Streamlining}

Late stage $\mathrm{C}-\mathrm{H}$ oxidation is a powerful approach for the streamlining and diversification of complex natural products and compounds of medicinal interest. ${ }^{22}$ With optimal conditions in hand, we sought to evaluate the performance of functionally and topologically complex substrates under our aerobic LAA reaction (Scheme 3). A glucose-derived substrate 21, bearing an abundance of oxygenated functionality, furnished the corresponding allylic amine 22 in $76 \%$ yield as a single diastereomer, after only 24 hours.

Estrone derivatives were evaluated in both their protected $\mathbf{2 3}$ and unprotected forms $\mathbf{2 5}$. When the aerobic LAA was applied to protected estrone derivative $\mathbf{2 3}$, the linear allylic amination product $\mathbf{2 4}$ was furnished in good yield $(64 \%) .{ }^{7 \mathrm{~b}}$ Based on previous results demonstrating the limited compatibility of Lewis basic functionality under our aerobic LAA conditions, we evaluated $\mathbf{2 5}$ under conditions employing 2,5-DMBQ (1 equiv.) as the stoichiometric oxidant. Gratifyingly, these conditions afforded the allylic amine product $\mathbf{2 6}$ in $50 \%$ yield using only 5 mol\% of palladium catalyst. ${ }^{7 \mathrm{~b}}$ These results demonstrate the applicability of these aerobic LAA conditions to afford useful yields of functionalized complex molecules, as well as the increase in reaction efficiency possible under conditions that limit detrimental Pd-quinone interactions.

Given the improved synthetic efficiency of the aerobic linear allylic amination with respect to both catalyst loadings and product yields, we sought to re-evaluate the LAA in the context of synthetic streamlining. The linear allylic $\mathrm{C}-\mathrm{H}$ amination reaction has been previously used in the context of a streamlined synthesis of $\mathbf{2 8}$, a rigidified analog of the antibiotic deoxynegamycin (Scheme 4). ${ }^{7 a}$ This $\mathrm{C}-\mathrm{H}$ to $\mathrm{C}-\mathrm{N}$ bond-forming route eliminated five steps, all of which were functional group manipulations, and proceeded with higher overall yield as compared to the previous route based on allylic $\mathrm{C}-\mathrm{O}$ substitution. ${ }^{7 \mathrm{a}, 23}$ When applying the new aerobic amination conditions to the key $\mathrm{C}-\mathrm{H}$ amination step of the previous synthesis, we were delighted to find that these optimized conditions afforded a nearly 30\% increase in yield of aminated intermediate 27 under either Co 2 or V 3 cocatalysis with $5 \mathrm{~mol} \%$ of Pd/bis-sulfoxide catalyst 1 (Scheme 4). The increased efficiency of this key $\mathrm{C}-\mathrm{N}$ bond-forming step now affords a 35\% overall yield of deoxynegamycin analog $\mathbf{2 8}$, a nearly three-fold increase in yield as compared to the $\mathrm{C}-\mathrm{O}$ to $\mathrm{C}-\mathrm{N}$ route. ${ }^{23}$

\section{THE BENZOQUINONE EFFECT}

We have demonstrated that the linear allylic amination (LAA) reaction run under aerobic conditions and conditions using bulky quinone terminal oxidants (2,5-DMBQ) lead to both improved product yields and catalyst turnover relative to the previous system relying on stoichiometric benzoquinone as the terminal oxidant. We hypothesized that the mechanistic basis for these differences is that at high concentrations, BQ acts as an inhibitory ligand for this Pd(II)/bis-sulfoxide catalysis (Table 5A). As a preliminary evaluation of this, we increased the concentration of $\mathrm{BQ}$ under the aerobic reaction conditions and measured the effect on overall yields. Strikingly, under both $\mathrm{Co}$ (salophen) 2 and $\mathrm{VO}(\mathrm{acac})_{2} \mathbf{3}$ co-catalysis, a significant diminishment in yield was observed (Table 5B, entries 1-3 and 4-6, respectively). 
Although stable palladium (0) benzoquinone complexes are known, palladium (II) benzoquinone complexes are fleeting and have been proposed as intermediates within catalytic cycles largely based on kinetic studies. ${ }^{24} \mathrm{In}$ the $\mathrm{Pd}(\mathrm{OAc})_{2}$-catalyzed diacetoxylation of 1,3-dienes using $\mathrm{MnO}_{2}$ as the stoichiometric oxidant, a linear dependence of reaction rate on benzoquinone concentration supported the hypothesis that BQ acts as a $\pi$ acidic ligand for $\mathrm{Pd}$ (II) to promote functionalization. ${ }^{5 a}$ In order to more definitively demonstrate the inhibitory effect of $\mathrm{BQ}$, we measured the rate of reaction under the aerobic LAA conditions- a scenario where an appreciable accumulation of dihydroquinone is unlikely- in the presence of increasing amounts of BQ. Reaction rates were measured at 5 $\mathrm{mol} \% \mathrm{Pd}(\mathrm{II}) /$ bis-sulfoxide 1 while varying the BQ concentration between 0.066 and $0.66 \mathrm{M}$ (10-100 mol\% relative to substrate). These experiments were performed in triplicate between 4-150 minutes of initiating the reaction (Figures S3 - S8, supporting information). A plot of the inverse of the reaction rate at various concentrations of $B Q$ is shown in Figure 1. The LAA reaction rate shows a clear inverse dependence on BQ: a 10-fold increase in $[\mathrm{BQ}]$ results in a nearly 9 -fold decrease in reaction rate.

Collectively, this data indicates that BQ has an inhibitory effect on the linear allylic amination (LAA) at high concentrations. While this is consistent with the hypothesis that interactions of $\mathrm{BQ}$ with the $\mathrm{Pd}(\mathrm{II}) / \mathrm{bis}$-sulfoxide catalyst are detrimental to reaction efficiency, future mechanistic studies will be directed at elucidating the precise mechanism for BQ inhibition.

\section{CONCLUSIONS}

We have demonstrated that using an $\mathrm{O}_{2} / \mathrm{Co} /$ catalytic dihydroquinone redox relay in combination with our Pd/bis-sulfoxide catalysis enables aerobic linear allylic aminations (LAA) of terminal olefins to proceed at reduced palladium catalyst loadings and higher reaction efficiency than the previous system relying on stoichiometric BQ. Kinetic experiments show for the first time an inhibitory effect of $\mathrm{BQ}$ on $\mathrm{Pd}(\mathrm{II})$ oxidative catalysis. Collectively this data implies that for reactions relying on Pd(II) catalysts with weakly coordinating ligands (e.g. bis-sulfoxide) to promote key steps in the catalytic cycle (e.g. C$\mathrm{H}$ cleavage), interactions of $\mathrm{BQ}$ when present in high concentrations with the $\mathrm{Pd}(\mathrm{II})$ catalyst may be detrimental to reaction efficiency. For such systems, adopting a system which uses molecular oxygen as a stoichiometric oxidant offers not only practical environmental benefits but may also lead to enhanced catalytic efficiency.

\section{EXPERIMENTAL PROCEDURE}

\section{General procedure for the linear allylic amination}

To an oven dried $10 \mathrm{~mL}$ round bottom flask containing a PTFE-covered stir bar was added: tetra $n$-butyl ammonium acetate in a glove box, followed by carbamate nucleophile, dihydroquinone, metal co-catalyst and catalyst $\mathbf{1}$. Due to the hygroscopic nature of TBAA, the reaction flask was not opened until all solids were ready to be transferred into the flask. The terminal olefin (pre-weighed in a $1 / 2$ dram vial) was transferred to the reaction flask using the corresponding solvent $(1 \mathrm{M})$. The flask was then attached to a cold-water condenser, previously purged briefly with oxygen, and equipped with an $\mathrm{O}_{2}$ balloon. The 
flask was secured with a Teflon adaptor, sealed with Teflon tape, and the reaction was allowed to stir at $400 \mathrm{rpm}$ in a $45^{\circ} \mathrm{C}$ oil bath for $24-72$ hours or until completed by TLC. Upon completion, a workup with an aqueous solution of $5 \% \mathrm{~K}_{2} \mathrm{CO}_{3}$ may be used to remove remaining nucleophile and water-soluble impurities. (Generally this workup leads to higher purity of isolated products). Alternatively, the reaction may diluted with dichloromethane and flushed through a 3-5 cm silica gel plug with an $80 \%$ ethyl acetate $/ 20 \%$ hexanes mixture to separate the product from metal catalysts. If no work-up is necessary, the reaction mixture may also be directly loaded onto a silica gel column using dichloromethane or toluene. Purification of the products is done using flash column chromatography - in general, with a gradient of 10-30\% EtOAc/hexanes. We have also found that 10-30\% acetone/hexanes or $10-50 \%$ ether/pentane gradients are effective solvent systems for purification.

For reactions run under air, the same general procedure outlined above was employed, the only change being a balloon of air was used. While the reaction condenser may be left opened to air, we have noted rapid and continual loss of the very volatile TBME solvent under this scenario and recommend the use of an air balloon.

\section{Supplementary Material}

Refer to Web version on PubMed Central for supplementary material.

\section{Acknowledgments}

Funding Sources

Financial support was provided by the NIH/NIGMS (2R01 GM 076153B) and ARRA supplemental funding.

We thank Sigma Aldrich for a generous gift of Pd/bis-sulfoxide catalyst (1) (product number 684821), Johnson Matthey for a generous gift of $\mathrm{Pd}(\mathrm{OAc})_{2}$, Anitox for a generous gift to explore a-olefin oxidations, Mr. Jeffrey D. Sayler for help with substrate synthesis and initial studies for Table 3 and Ms. Jennifer R. Griffin and Mr. Stephen E. Ammann for checking the experimental procedure in Table 2, entry 2.

\section{References}

1. (a) Berkessel, A. Diversity-Based Approaches to Selective Biomimetic Oxidation Catalysis. In: van Eldik, R.; Reedijk, J., editors. Advances in Inorganic Chemistry. Vol. 58. Elsevier; 2006. p. 1-28.(b) Ortiz de Montellano PR. Chem Rev. 2010; 110:932. [PubMed: 19769330]

2. (a) Stahl SS. Angew Chem Int Ed. 2004; 43:3400.(b) Piera J, Bäckvall JE. Angew Chem Int Ed. 2008; 47:3506.(c) Cavani F, Teles JH. Chem Sus Chem. 2009; 2:508.

3. Moiseev II, Vargaftik MN, Syrkin YK. Dokl Akad Naak SSSR. 1960; 133:377.

4. Popp, BV.; Stahl, SS. Palladium-Catalyzed Oxidation Reactions: Comparison of Benzoquinone and Molecular Oxygen as Stoichiometric Oxidants. In: Meyer, F.; Limberg, C., editors. Topics in Organometallic Chemistry;. Vol. 22. Springer; New York: 2007. p. 149-189.

5. (a) Bäckvall JE, Byström SE, Nordberg RE. J Org Chem. 1984; 49:4619.(b) Castaño AM, Bäckvall JE. J Am Chem Soc. 1995; 117:560.(c) Chen MS, Prabagaran N, Labenz NA, White MC. J Am Chem Soc. 2005; 127:6970. [PubMed: 15884938] (d) Bar GLJ, Lloyd-Jones GC, Booker-Milburn KI. J Am Chem Soc. 2005; 127:7308. [PubMed: 15898768] (e) Chen X, Li JJ, Hao XS, Goodhue CE, Yu JQ. J Am Chem Soc. 2006; 128:78. [PubMed: 16390130] (f) Fraunhoffer KJ, Prabagaran N, Sirois LE, White MC. J Am Chem Soc. 2006; 128:9032. [PubMed: 16834366] (g) Covell DJ, White MC. Angew Chem Int Ed. 2008; 47:6448.(h) Hull KL, Sanford SS. J Am Chem Soc. 2009; 
131:9651. [PubMed: 19569623] (i) Osberger TJ, White MC. J Am Chem Soc. 2014; 136:11176. [PubMed: 24999765]

6. (a) Chen MS, White MC. J Am Chem Soc. 2004; 126:1346. [PubMed: 14759185] (b) Fraunhoffer KJ, White MC. J Am Chem Soc. 2007; 129:7274. [PubMed: 17516648] (c) Young AJ, White MC. J Am Chem Soc. 2008; 130:14090. [PubMed: 18831588] (d) Lin S, Song CX, Cai GX, Wang WH, Shi ZJ. J Am Chem Soc. 2008; 130:1290.(e) Rice GT, White MC. J Am Chem Soc. 2009; 131:11707. [PubMed: 19645489] (f) Nahra F, Liron F, Prestat G, Mealli C, Messaoudi A, Poli G. Chem Eur J. 2009; 15:11078. [PubMed: 19795438] (g) Stang EM, White MC. J Am Chem Soc. 2011; 133:14892. [PubMed: 21842902] (h) Braun MG, Doyle AG. J Am Chem Soc. 2013; 135:12901.

7. (a) Reed SA, White MC. J Am Chem Soc. 2008; 130:3316. [PubMed: 18302379] (b) Reed SA, Mazotti AR, White MC. J Am Chem Soc. 2009; 131:11701. [PubMed: 19645492]

8.

Collet F, Dodd RH, Dauban P. Chem Commun. 2009:5061., and references therein. Jeffrey JL, Sarpong R. Chem Sci. 2013; 4:4092., and references therein. Paradine SM, Griffin JR, Zhao J, Petronico AL, Miller SM, White MC. Nature Chem. 2015; 7:987. [PubMed: 26587714]

9.

For examples of aerobic olefin oxidation, see: Larock RC, Hightower TR, Hasvold LA, Peterson KP. J Org Chem. 1996; 61:3584. [PubMed: 11667199] Brice JL, Harang JE, Timokhin VI, Anastasi NR, Stahl SS. J Am Chem Soc. 2005; 127:2868. [PubMed: 15740119] For examples of aerobic alcohol oxidation, see: Jensen DR, Pugsley JS, Sigman MS. J Am Chem Soc. 2001; 123:7475. [PubMed: 11472200] Ferreira EM, Stoltz BM. J Am Chem Soc. 2001; 123:7725. [PubMed: 11481006] For examples of aerobic C-H oxidation, see Zhang YH, Yu JQ. J Am Chem Soc. 2009; 131:14654. [PubMed: 19788192] and references 8,9,10 and 15

10. (a) Sigman MS, Schultz MJ. Org Biomol Chem. 2004; 2:2551. [PubMed: 15351815] (b) Gladysz JA, Bedford RB, Fujita M, Gabbaï FP, Goldber KI, Holland PL, Kiplinger JL, Krische MJ, Louie J, Lu CC, Norton JR, Petrukhina MA, Ren T, Stahl SS, Tilley DT, Webster CE, White MC, Whiteker GT. Organometallics. 2014; 33:1505.

11. Mitsudone T, Umetani T, Nosaka N, Mori K, Mizugaki T, Ebitani K, Kaneda K. Angew Chem Int Ed. 2006; 45:481.

12. Liu G, Yin G, Wu L. Angew Chem Int Ed. 2008; 47:4733.

13. Shimizu Y, Obora Y, Ishii Y. Org Lett. 2010; 12:1372. [PubMed: 20158264]

14. Yin G, Wu Y, Liu G. J Am Chem Soc. 2010; 132:11978. [PubMed: 20690676]

15. Campbell AN, White PB, Guzei IA, Stahl SS. J Am Chem Soc. 2010; 132:15116. [PubMed: 20929224]

16. (a) Smidt J, Hafner W, Jira R, Sedlmeier J, Sieber R, Ruttinger R, Kojer H. Angew Chem. 1959; 71:176.(b) Henry PM, Keith JA. Angew Chem Int Ed. 2009; 48:9038.

17. (a) Németh S, Szeverény Z, Simándi LI. Inorganica Chimica Acta. 1980; 44:107.(b) Rio MF, Pujol D, Charreton CB, Fauvet MP, Gaudemer AJ. Chem Soc Perkin Trans. 1984; 1:1971.

18. (a) Tatsuno Y, Tatsuda M, Otsuka S. J Chem Soc,Chem Commun. 1982:1100.(b) Hwang DR, Chu CY, Wang SK, Uang BJ. Synlett. 1999; 1:77.

19. (a) Bäckvall JE, Awasthi AK, Renko ZD. J Am Chem Soc. 1987; 109:4750.(b) Bäckvall JE, Hopkins RB, Grennberg H, Mader MM, Awasthi AK. J Am Chem Soc. 1990; 112:5160.

20. Schaus SE, Brandes BD, Larrow JF, Tokunaga M, Hansen KB, Gould AE, Furrow ME, Jacobsen EN. J Am Chem Soc. 2002; 124:1307. [PubMed: 11841300]

21. (a) Witt A, Teodorovic P, Linderberg M, Johansson P, Minidis A. Org Process Res Dev. 2013; 17:672.(b) Osterberg PM, Niemeier JK, Welch CJ, Hawkins JM, Martinelli JR, Johnson TE, Root TW, Stahl SS. Org Process Res Dev. 2014; 19:1537. [PubMed: 26622165]

22. (a) Fraunhoffer KJ, Bachovchin DA, White MC. Org Lett. 2005; 7:223. [PubMed: 15646963] (b) Chen MS, White MC. Science. 2007; 318:783. [PubMed: 17975062] (c) Stang EM, White MC. Nature Chem. 2009; 1:547. [PubMed: 21378935] (d) Kim J, Ashenhurst JA, Movassaghi M. Science. 2009; 324:238. [PubMed: 19359584] (e) Chen K, Baran PS. Nature. 2009; 459:824. 
[PubMed: 19440196] (f) Chen MS, White MC. Science. 2010; 327:566. [PubMed: 20110502] (g) Malik HA, Taylor BL, Kerrigan JR, Grob JE, Houk KN, Dubois JN, Hamman LG, Patterson AW. Chem Sci. 2014; 5:2352. [PubMed: 25685311] (h) He J, Hamann LG, Davies HML, Beckwith REJ. Nat Commun. 2015; 6:5943. [PubMed: 25581471]

23. Raju B, Anandan S, Gu S, Herradura P, O’Dowd H, Kim B, Gomez M, Hackbarth C, Wu C, Wang W, Yuan Z, White R, Trias J, Patel DV. Bioorg Med Chem Lett. 2004; 14:3103. [PubMed: 15149653]

24.

For spectroscopic evidence of $\pi$-allylPd(II)/BQ complexes see: Bäckvall JE, Gogoll A. Tetrahedron Lett. 1988; 29:2243. 
$1(5 \mathrm{~mol} \%)$

$\mathrm{Co}$ (II) salophen (2.5 mol\%)

$\mathrm{TsNHCO}_{2} \mathrm{Me}$ (1.5 equiv.)<smiles>C=CCc1ccccc1OC</smiles>

TBAA (6 mol\%)

$B Q(10-100 \mathrm{~mol} \%)$

TBME $(0.66 \mathrm{M})$

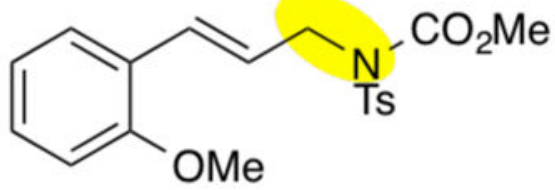

1 equiv.

$\mathrm{O}_{2}(1 \mathrm{~atm}), 45^{\circ} \mathrm{C}$

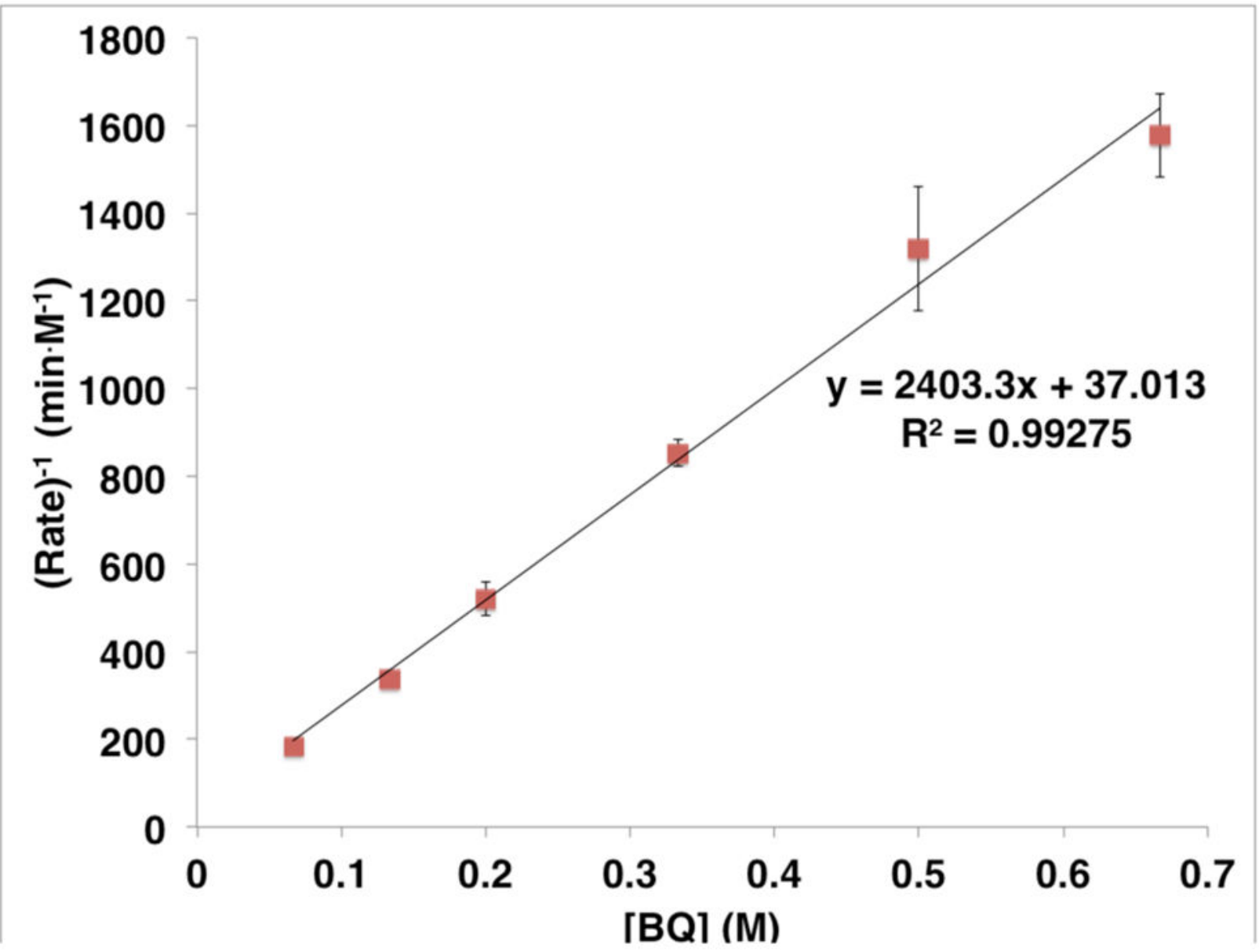

Figure 1.

Inverse Relationship Between Rate and BQ Concentration. 


\section{A. Serial Ligand Catalysis Disrupted}

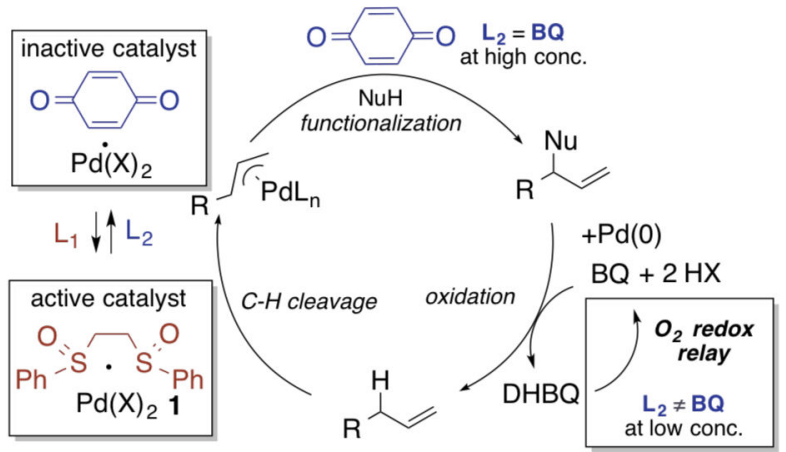

\section{B. Previous Work}

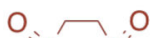

$$
\mathrm{Ph} \text { Pd } \mathrm{Pd}(\mathrm{OAc})_{2} \mathrm{Ph}
$$
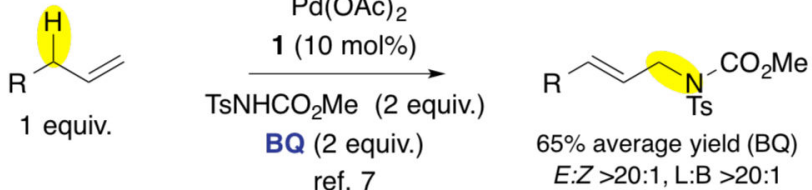

1 equiv.

ref. 7

\% average yield (BQ)

C. This Work

1 (2.5-5 mol\%)

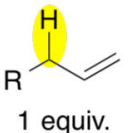

$\mathrm{Co}(\mathrm{II})$ salophen (2.5 mol\%)

$\mathrm{TsNHCO}_{2} \mathrm{Me}$ ( 1.5 equiv.)

$\mathrm{DHBQ}$ (10 mol\%)

$\mathrm{O}_{2}$ or air (1 atm.)

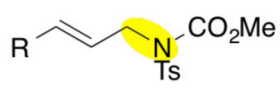

$73 \%$ average yield $\left(\mathrm{O}_{2}\right)$

$E: Z>20: 1, L: B>20: 1$

Scheme 1.

BQ Ligand Effects in Intermolecular Allylic C-H Amination. 


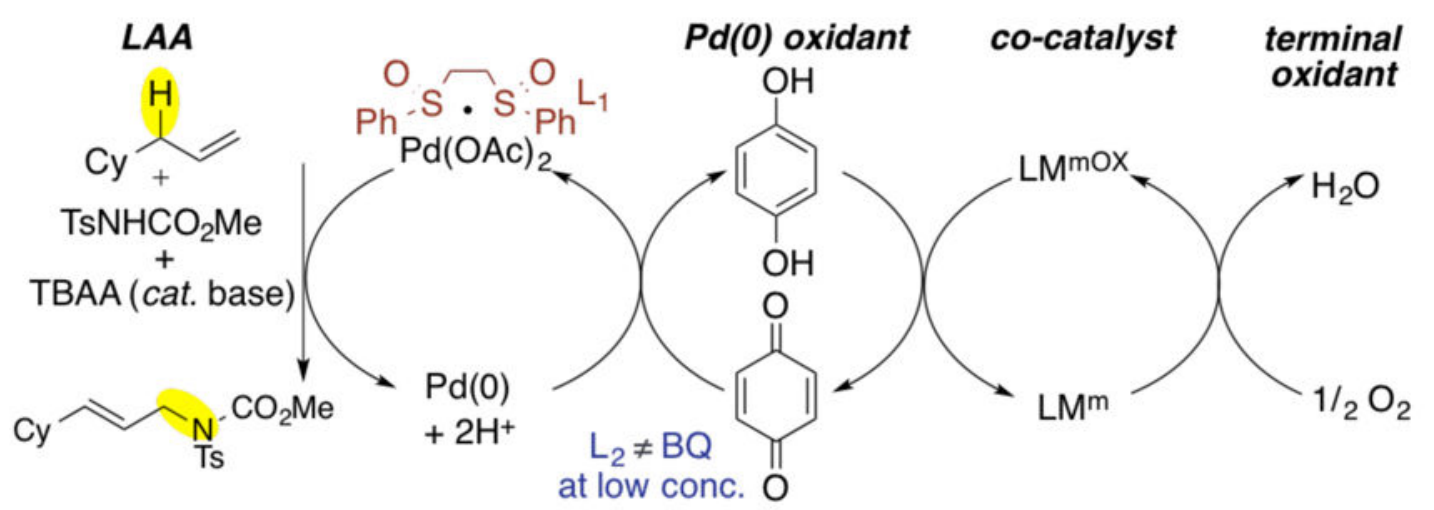

Scheme 2.

Proposed Mechanism for Aerobic Linear Allylic Amination (LAA) With Redox-Relay Catalysis 
<smiles>C=CC[C@H]1OC(COC(C)=O)[C@H](OC(C)=O)C(OC(C)=O)[C@H]1OC(C)=O</smiles>

(+)-21 1 equiv.

\section{aerobic LAA}

$\mathrm{O}$
$\mathrm{Ph}_{\mathrm{Pd}(\mathrm{OAc})_{2}} 1$

(5 mol\%)

$\mathrm{L}_{n} \mathrm{Co}$ (II) 2 (2.5 mol\%)

$\mathrm{TsNHCO}_{2} \mathrm{Me}$ (1.5 equiv.)

TBME, $\mathrm{O}_{2}$ (1 atm)<smiles>CC(=O)OCC1O[C@H](/C=C/CN(S)C(C)=O)C(OC(C)=O)[C@H](OC(C)=O)[C@H]1OC(C)=O</smiles>

(+)-22

$76 \%$ yield

(24 hrs.)<smiles>C=CC[C@H]1C[C@H]2[C@H]3CCc4cc(OC(C)C)ccc4[C@H]3CCC2(C)[C@H]1OC(C)=O</smiles>

(+)-23

1 equiv.

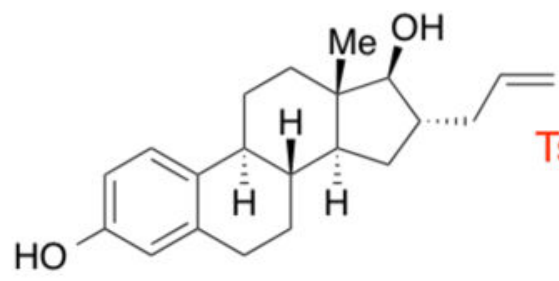

aerobic LAA<smiles>COC(=O)[NH2+]C/C=C/[C@H]1C[C@H]2[C@H]3CCc4cc(OC(C)=S)ccc4[C@@H]3CCC2(C)[C@H]1OC(C)=O</smiles>

(-)-24

$64 \%$ Yield<smiles>COC(=O)[NH2+]C/C=C/[C@H]1C[C@H]2[C@@H]3CCc4cc(O)ccc4[C@H]3CC[C@@]2(C)[C@@H]1O</smiles>

$(+)-25$

1 equiv.

TBME

1 equiv.

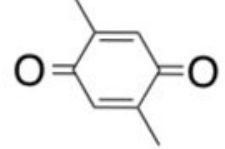

(+)-26

$50 \%$ yield

Scheme 3.

Reactivity of Functionally Diverse Substrates. 


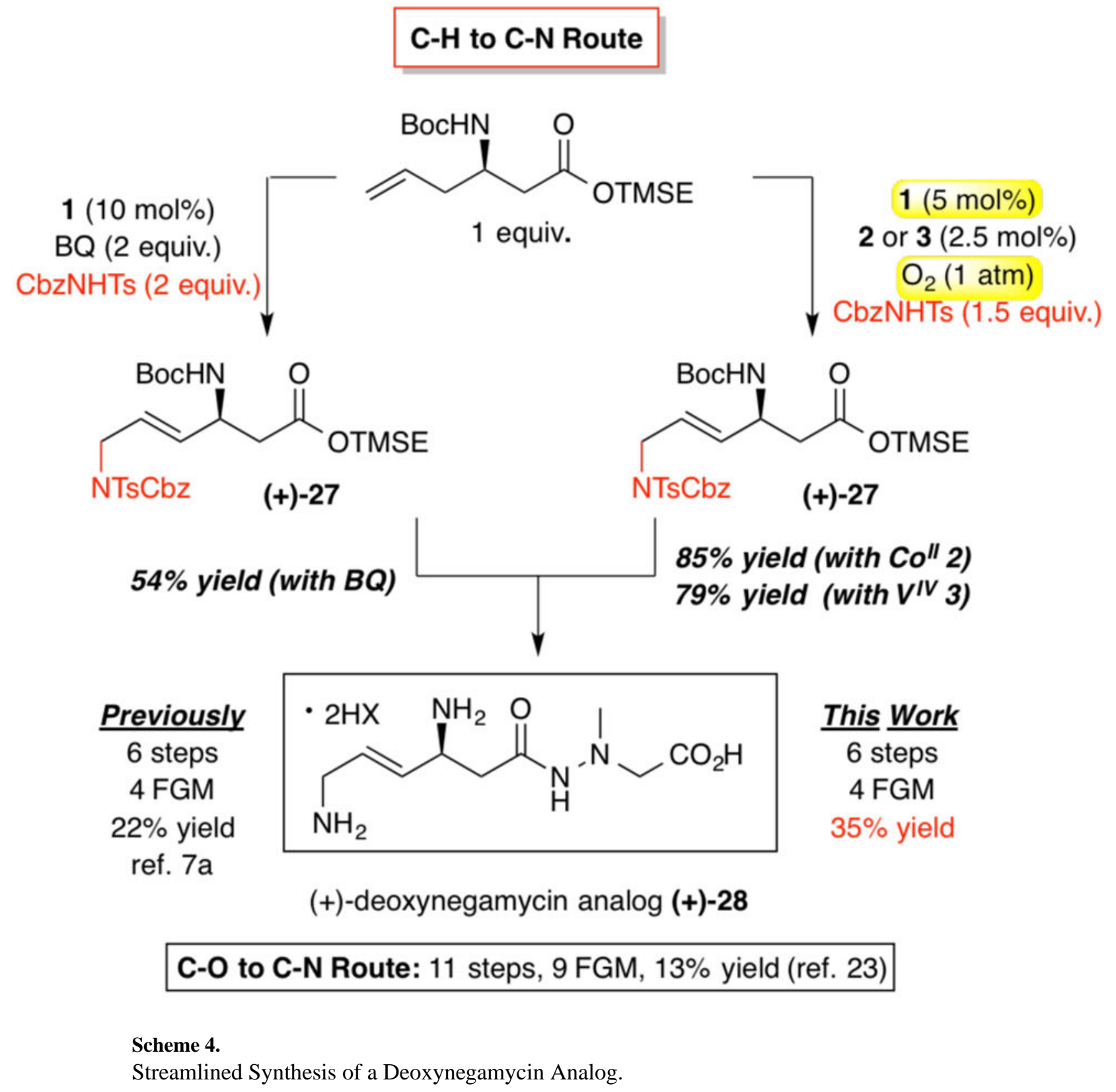




\section{Table 1}

Reaction Optimization.

\begin{tabular}{|c|c|c|c|c|c|}
\hline \multicolumn{2}{|c|}{ 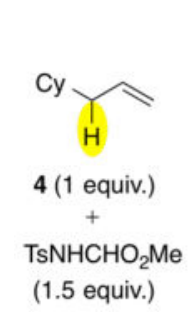 } & \multicolumn{2}{|c|}{ 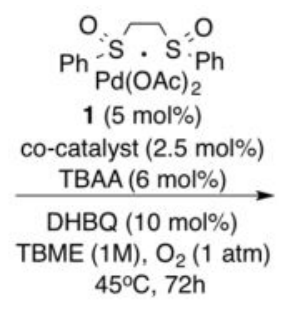 } & \multicolumn{2}{|c|}{ 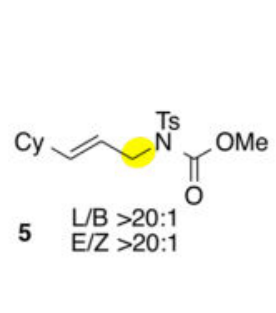 } \\
\hline Entry $^{a}$ & catalys & st/co-catalyst & Oxi & dant & Yield of $5^{b}$ \\
\hline $1^{c}$ & & mol\% 1/-- & BQ (2 & equiv.) & $84 \%$ \\
\hline $2^{c}$ & & $\mathrm{~mol} \% \mathrm{1} /--$ & BQ $(2$ & equiv.) & $20 \%$ \\
\hline $3^{d}$ & 1/Co(Il & I)(salophen) 2 & $\mathrm{O}_{2}($ & atm) & $68 \%$ \\
\hline 4 & 1/Co(Il & I)(salophen) 2 & $\mathrm{O}_{2}($ & $\mathrm{atm})$ & $79 \%(78 \%)^{e}$ \\
\hline 5 & $1 / \mathrm{C}$ & $\mathrm{O}(\mathrm{II})(\mathrm{TPP})$ & $\mathrm{O}_{2}($ & $\mathrm{atm})$ & $60 \%$ \\
\hline 6 & $1 / \mathrm{Cc}$ & o(II)(salen) & $\mathrm{O}_{2}($ & $\mathrm{atm})$ & $74 \%$ \\
\hline 7 & $1 / \mathrm{Mr}$ & n(III)(salen) & $\mathrm{O}_{2}($ & $\mathrm{atm})$ & $8 \%$ \\
\hline 8 & & $/ \mathrm{Fe}(\mathrm{II}) \mathrm{Pc}$ & $\mathrm{O}_{2}($ & atm) & $39 \%$ \\
\hline 9 & $1 / \mathrm{V}$ & $\mathrm{O}(\mathrm{acac})_{2} \mathbf{3}$ & $\mathrm{O}_{2}($ & $\mathrm{atm})$ & $48 \%$ \\
\hline $10^{f}$ & $1 / \mathrm{V}$ & $\mathrm{O}(\mathrm{acac})_{2} \mathbf{3}$ & $\mathrm{O}_{2}($ & atm) & $75 \%(80 \%)^{g}$ \\
\hline $11^{f}$ & & /VO(TPP) & $\mathrm{O}_{2}($ & atm) & $53 \%$ \\
\hline $12^{f}$ & $1 / \mathrm{VO}$ & O(Salophen) & $\mathrm{O}_{2}($ & atm) & $54 \%$ \\
\hline${ }_{13} f, h$ & & /VOSO4 & $\mathrm{O}_{2}($ & & $65 \%$ \\
\hline 14 & & 1/-- & $\mathrm{O}_{2}$ & atm) & $17 \%$ \\
\hline $15^{i}$ & $\operatorname{Pd}(C$ & $\mathrm{OAc})_{2} / \mathrm{DAF}$ & $\mathrm{O}_{2}($ & atm) & trace \\
\hline $16^{c}$ & & $1 /--$ & 2,5-DMB & (1 equiv.) & $72 \%$ \\
\hline
\end{tabular}

${ }^{a}$ Conditions are as listed above unless noted. Co(II)(salophen) $=$ N,N'-Bis(salicylidene)-1,2-phenylenediamino cobalt(II); $\mathrm{Co}(\mathrm{II})(\mathrm{TPP})=5,10,15$, 20-Tetraphenyl-21H,23H-porphine cobalt (II); $\mathrm{Co}(\mathrm{III})($ salen $)=(\mathrm{R}, \mathrm{R})-\mathrm{N}, \mathrm{N}^{\prime}-\mathrm{Bis}(3,5$-di-tert-butylsalicylidene)-1,2- cyclohexanediaminocobalt(II); $\mathrm{Mn}(\mathrm{II})(\mathrm{salen})=(\mathrm{R}, \mathrm{R})-(-)-\mathrm{N}, \mathrm{N}^{\prime}$-Bis(3,5-di-tert-butylsalicylidene)-1,2-cyclohexanediaminomanganese(III) chloride; Fe(II)Pc = Iron(II) phthalocyanine; $\mathrm{VO}($ acac $) 2=$ vanadyl acetylacetonate; $\mathrm{VO}(\mathrm{TPP})=5,10,15,20$-Tetraphenyl-21H, 23H-porphinevanadium $(\mathrm{IV})$ oxide; $\mathrm{VO}($ salophen $)=$ $\mathrm{N}, \mathrm{N}^{\prime}$-bis(salicylidene)-1,2-phenylen ediaminovanadium(IV) oxide.

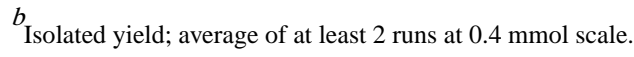

${ }^{c}$ Conditions from ref. $7 \mathrm{~b}$.

$d_{1 \mathrm{M} \text { TBME, } 2 \text { equiv. TsNHCO}} \mathrm{Me}$.

e Number in parenthesis is yield at $24 \mathrm{~h}$.

$f_{2 \text { equiv. TsNHCO}} \mathrm{Me}, 1 \mathrm{M}$ THF.

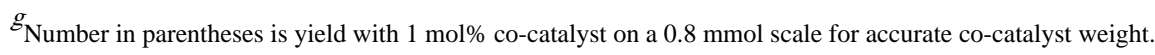

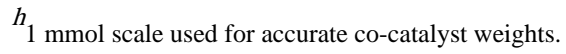


$i_{5 \mathrm{~mol} \%} \mathrm{Pd}(\mathrm{OAc}) 2,5 \mathrm{~mol} \%$ 4,5- diazafluorene-9-one (DAF), with identical conditions to entries 4-9. 


\section{Table 2}

Aliphatic Substrates.

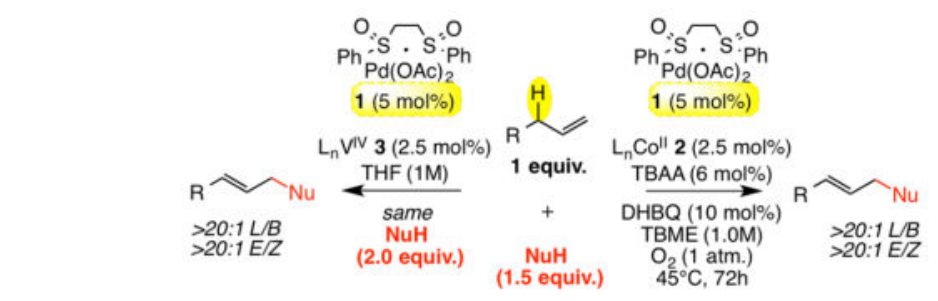

\begin{tabular}{|c|c|c|c|c|}
\hline \multirow[b]{2}{*}{ Entry } & \multirow[b]{2}{*}{ Product } & \multicolumn{2}{|c|}{ This Work } & Previously \\
\hline & & $\mathrm{Co}^{a}, \boldsymbol{b}$ & $\mathrm{v}^{a, c}$ & $\mathrm{BQ}$ or $\mathrm{O}_{2}$ \\
\hline
\end{tabular}

6<smiles>CON(C)CC=CCCCOc1ccccc1</smiles>
$54 \%{ }^{e}(30 \%) f_{[ \pm 2 \%]} \quad 44 \%[ \pm 14 \%]$

2

7<smiles>CO[N+](=O)CC=CCCO[Na]</smiles>
$\begin{array}{lll}75 \%{ }^{g}(70 \%)^{f} & 81 \% & 78 \%{ }^{h} \\ & & 92 \cdot 8^{i}\end{array}$

8<smiles>CON(C)CC=CC1CCCCC12OCCO2</smiles>

$67 \% \quad 58 \% \quad 53 \% j$

4

9

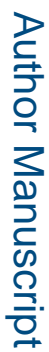

5<smiles>CONC(=O)C(C)/C=C/CNC(=O)OC</smiles>
$55 \%$ $23 \%^{k} \quad 54 \% 1$

$(+)-10$<smiles>CC(=O)N[C@@H](/C=C/CN([AsH3+])C(C)=O)CC(=O)OC(C)(C)C</smiles>

$86 \%$ $15 \%^{k} \quad 55 \% 1$

(+)-11<smiles>COCNCC=CCC(COC)O[Na]</smiles>

$69 \%$

$65 \% 1$

(+)-12

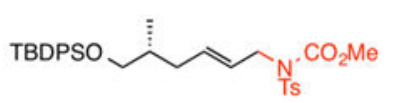

$77 \%$

$67 \%$

$57 \% 1$

$(+)-13$

Isolated yield, average of at least 2 runs at $0.4 \mathrm{mmol}$ scale.

$b_{5 \mathrm{~mol} \%} 1,2.5 \mathrm{~mol} \%$ 2, 6 mol$\%$ TBAA, $10 \mathrm{~mol} \%$ DHBQ, 1.5 equiv. TsNHCO $2 \mathrm{Me}, 1 \mathrm{M}$ TBME, $\mathrm{O}_{2}$ balloon.

$c_{5}$ mol $\%$ 1, 2.5 mol $\%$ 3, 6 mol\% TBAA, 10 mol\% DHBQ, 2 equiv. TsNHCO 2 Me, $1 \mathrm{M}$ THF, $\mathrm{O}_{2}$ balloon.

J Am Chem Soc. Author manuscript; available in PMC 2016 April 14. 
$d_{20: 1 \mathrm{~L}: \mathrm{B} .}$

$e_{11: 1 \mathrm{E}: Z, 11: 1 \mathrm{~L}: \mathrm{B} .}$

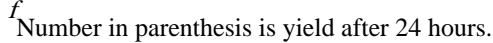

$g_{15: 1 \mathrm{~L}: \mathrm{B} .}$

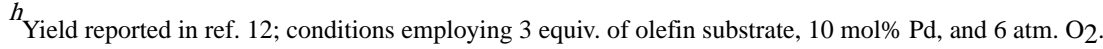

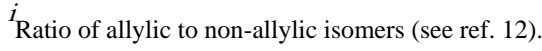

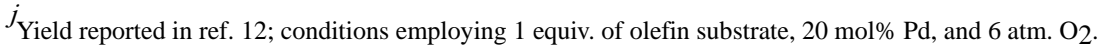

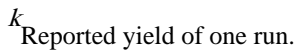

1 Yield reported in ref. 7a. 


\section{Table 3}

Aromatic substrates.

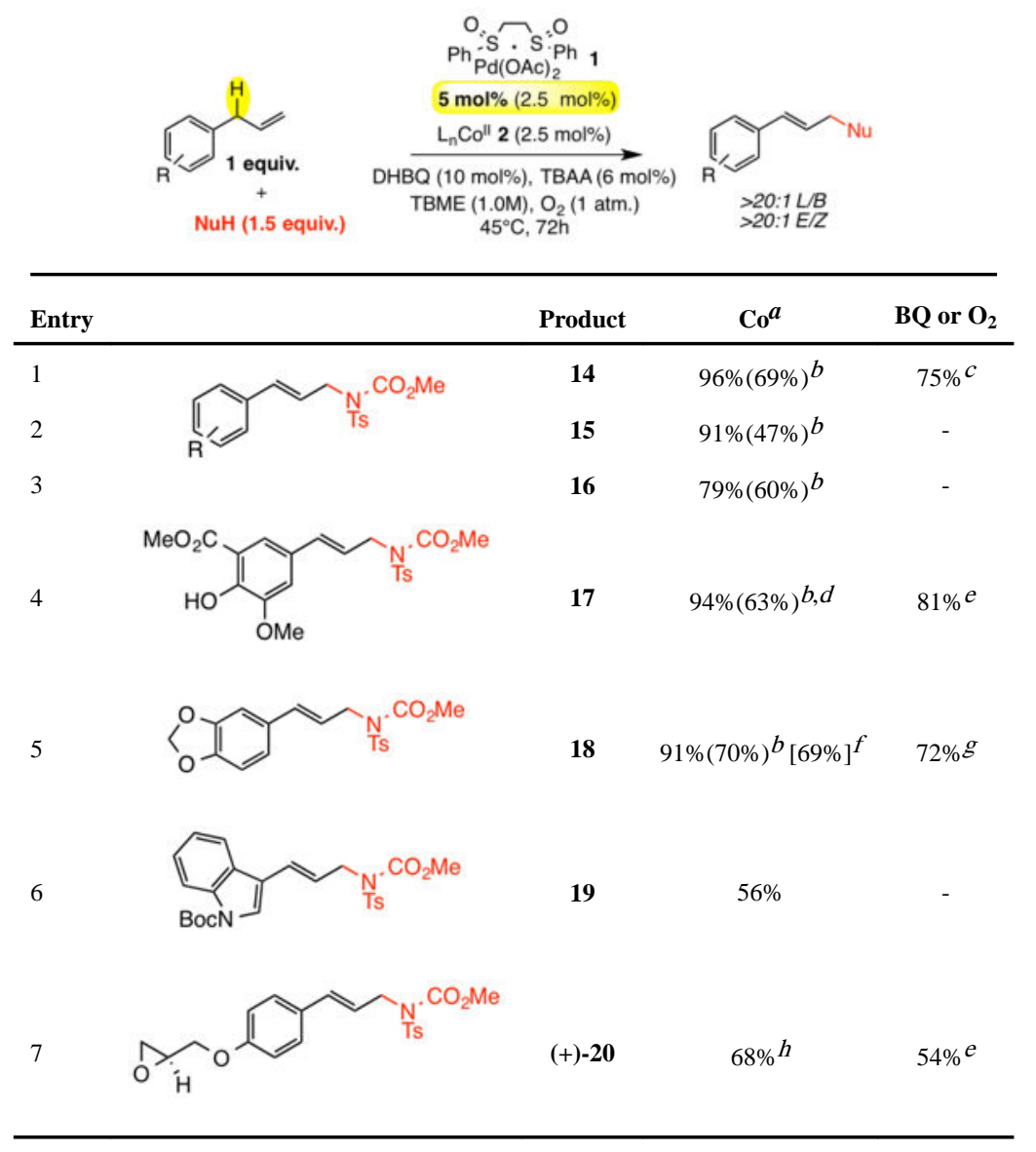

asolated yield, average of at least 2 runs at $0.4 \mathrm{mmol}$ scale.

$b_{2.5 \mathrm{~mol} \%} 1$ was used.

${ }^{c}$ Yield reported in ref. 12; conditions employing 3 equiv. of olefin substrate, $10 \mathrm{~mol} \% \mathrm{Pd}$, and 6 atm. $\mathrm{O}_{2}$.

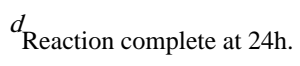

$e^{e}$ Yield reported in ref. $7 \mathrm{~b}$.

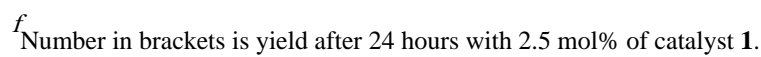

$g_{\text {Yield reported in ref. 7a. }}$

$h_{5 \mathrm{~mol} \%} 1,6 \mathrm{~mol} \%$ DIPEA, 1 equiv. 2,5-DMBQ, $0.66 \mathrm{M}$ TBME, 2 equiv. $\mathrm{TsNHCO}_{2} \mathrm{Me}, 45^{\circ} \mathrm{C}, 24 \mathrm{~h}$ (reaction performed on a $0.3 \mathrm{mmol} \mathrm{scale}$ ). 


\section{Table 4}

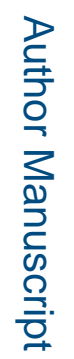

Allylic C-H Amination Using Air

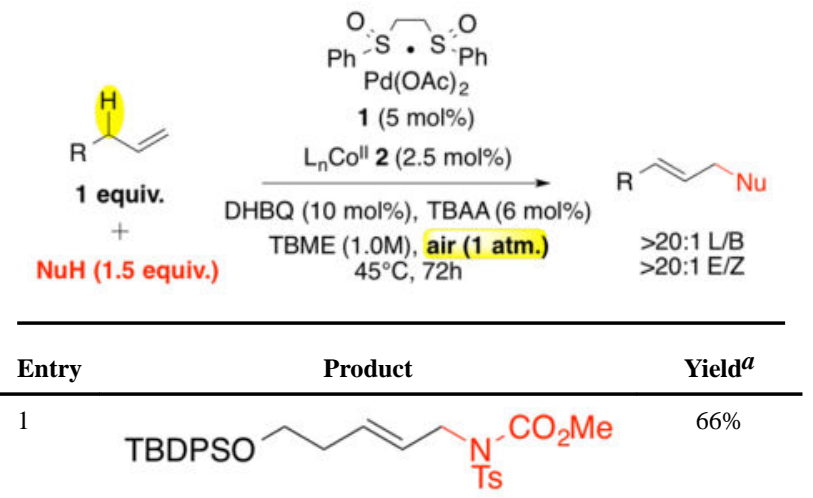

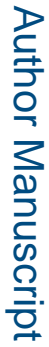

2

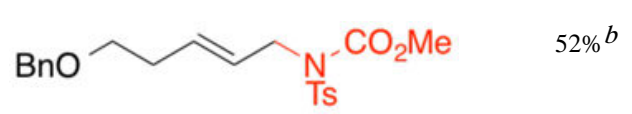

7

3<smiles>CC(=O)N([AsH3])C/C=C/C1CCCCC12OCCO2</smiles>

$57 \%$

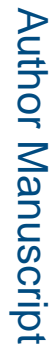<smiles>CC(=O)OC[C@H]([OH+])C/C=C/CN(C)C(C)=O</smiles>

$59 \%$

$(+)-12$

5<smiles>COc1ccccc1/C=C/CN(C)C(C)=O</smiles>

$62 \%^{c}$

14

6

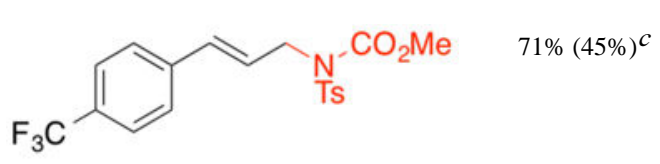

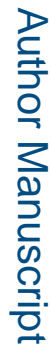

16

7<smiles>CC(=O)N([AsH3])C/C=C/c1ccc2c(c1)OCO2</smiles>

18

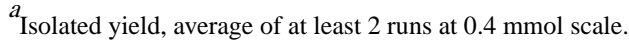

$b_{11: 1 \mathrm{E} / \mathrm{Z}}$

$c_{2.5 \mathrm{~mol} \% 1 \text { was used. }}$ 


\section{Table 5}

Effect of Elevated BQ on Reaction Yields.

\section{A. Catalyst Inhibition by Benzoquinone}

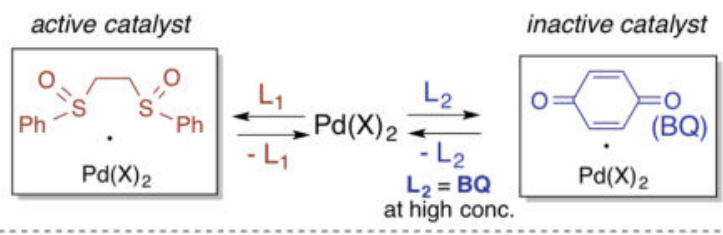

B. Preliminary Investigation of $B Q$ Inhibition

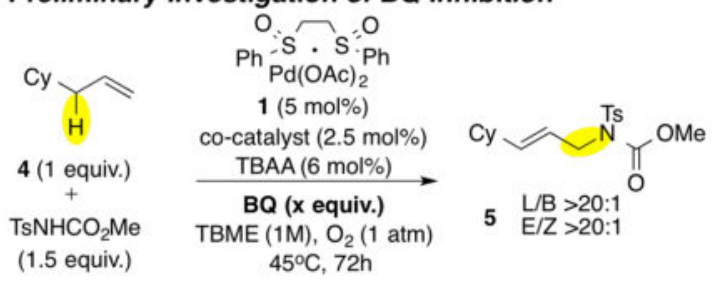

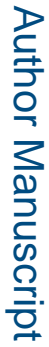

\begin{tabular}{lccc}
\hline Entry $\boldsymbol{a}$ & co-catalyst & BQ equivalents & Yield of $\mathbf{5}^{\boldsymbol{b}}$ \\
\hline 1 & $\mathrm{Co}(\mathrm{II})($ salophen) $\mathbf{2}$ & 0.1 equiv. & $81 \%$ \\
2 & $\mathrm{Co}(\mathrm{II})($ (salophen) $\mathbf{2}$ & 0.5 equiv. & $56 \%$ \\
3 & $\mathrm{Co}(\mathrm{II})(\mathrm{salophen)} \mathbf{2}$ & 1 equiv. & $50 \%$ \\
4 & $\mathrm{VO}(\mathrm{acac})_{2} \mathbf{3}$ & 0.1 equiv. & $70 \%$ \\
5 & $\mathrm{VO}(\mathrm{acac})_{2} \mathbf{3}$ & 0.5 equiv. & $40 \%$ \\
6 & $\mathrm{VO}(\mathrm{acac})_{2} \mathbf{3}$ & 1 equiv. & $25 \%$ \\
\hline
\end{tabular}

${ }^{a}$ Conditions are as listed above unless otherwise noted.

$b_{\text {Isolated yield; average of two runs at a } 0.4 \mathrm{mmol} \text { scale. }}$ 